\title{
INTERNET OF THINGS IN INDUSTRY 4.0 CASE STUDY: FLUID DISTRIBUTION MONITORING SYSTEM
}

\author{
Maroua Abdelhafidh ${ }^{1,2,3}$, Mohamed Fourati ${ }^{1,2,4}$, Lamia Chaari Fourati ${ }^{1,2,4}$ \\ and Abdessalam Chouaya ${ }^{5}$ \\ ${ }^{1}$ Laboratory of Technology and Smart Systems (LT2S), \\ University of Sfax, Tunisia \\ ${ }^{2}$ Digital Research Center of Sfax (CRNS) \\ ${ }^{3}$ National Engineering School of Sfax, Tunisia \\ ${ }^{4}$ Higher Institute of Computer Science and Multimedia of Sfax \\ ${ }^{5}$ Research Center Gafsa Chemical Group (SIAPE), Gafsa, Tunisia
}

\begin{abstract}
Internet of Things (IoT) is an emergent technology that provides a promising opportunity to improve industrial systems by the smartly use of physical objects, systems, platforms and applications that contain embedded technology to communicate and share intelligence with each other. In recent years, a great range of industrial IoT applications have been developed and deployed. Among these applications, the Water and Oil \& Gas Distribution System is tremendously important considering the huge amount of fluid loss caused by leakages and other possible hydraulic failures. Accordingly, to design an accurate Fluid Distribution Monitoring System (FDMS) represents a critical task that imposes a serious study and an adequate planning. This paper reviews the current state-of-the-art of IoT, major IoT applications in industries and focus more on the Industrial IoT FDMS (IIoT FDMS).
\end{abstract}

\section{KEYWORDS}

Industry applications, Internet of Things, Fluid Distribution System, Water loss, Oil and Gas loss

\section{INTRODUCTION}

Nowadays, Internet of Things (IoT) also known as Internet of Objects becomes an emergent technology that is widely used by several application domains. Thanks to its advanced services, the International Telecommunication Union (ITU) defines it as a global infrastructure for the Information Society, enabling advanced services by interconnecting (physical and virtual) things based on, existing and evolving, interoperable information and communication technologies [1]. Diverse fields of applications adapt IoT in their main implementation process. The most prominent areas of application include the smart home, smart energy, healthcare, manufacturing, transport, environment, smart industry and so on. Smart Industry or called also industry 4.0 is the core of IoT and smart manufacturing [2]. Intelligent techniques and flexible models used to perform a real-time monitoring make this technology a great solution for several challenges. In Other hand, the fluid monitoring is considered as a required task that must be improved in order to save environments from fluid losses and maintain a balanced system. IoT Technology is more and more investigated in this monitoring area and different researches are curried to propose,

Natarajan Meghanathan et al. (Eds) : NeTCoM, CSEIT, GRAPH-HOC, NCS, SIPR - 2017

pp. 01- 11, 2017. (C) CS \& IT-CSCP 2017

DOI : $10.5121 /$ csit.2017.71501 
implement and evaluate IoT-enabled solutions for Fluid Distribution System (FDS). In fact, thanks to its diverse employed devices, the data collection phase is able to sense all fluid parameters that will be transmitted wirelessly to a remote control server where the data processing and management will be done. This multi-layer architecture allows a real-time supervision and helps the operator to make the appropriate decision in case of damage in the system. This harmony of IoT subsystems is the crucial way to solve the majority of supervision problems in an efficient manner. In this paper, we will review the applications based on IoT technology. We will detail their performance and then we will focus on IoT in the FDS applications. The rest of paper is organized as follows: section II represents the Industrial IoT and its various applications. Section III details IIoT in Fluid Distribution Monitoring system. In section IV, a synthesis is carried out where we compare between the existing IoT-based applications for FDMS and evaluate their robustness. Section V illustrates the challenges of IIOTFDMS. Finally, section VI concludes this paper.

\section{INTERNET OF THINGS IN INDUSTRY 4.0}

Industries experience a technological revolution. Thus, at the beginning, companies and organizations employed manual monitoring methods and traditional services that required a lot of resources and led to a waste of time which can disturb the system operation. After that, by keeping pace with the industrial revolution that has largely changed the industry foundations and the economy, the industry has recognized rapid alterations from industry 1.0 to industry 4.0 [3]. In fact, in version 1.0 and 2.0, these industries used traditional monitoring ways based on nontechnical methods manually making transaction report. Then, the third version introduced the deployment of digital sensors measurement leading to the control automation. Recently, an hybrid entities such as the Human Internet Of Things and the Industrial Internet are investigated with various technologies such as the Information Technology (IT) and the Operating Technology (OT). Accordingly, a change in industry's approach based on heterogeneous data provided by various objects in order to be analyzed with smart manner and operational hardware and software is used to detect and locate possible impediments [4]. With the new concept of Industry 4.0, various IoT applications are developed in different industries as highlighted in [5] [6] [7]. These applications include environmental monitoring, healthcare service, smart agriculture, food supply chain, security, manufacturing, and surveillance.

- IoT in healthcare Industry: this application domain is one of the largest and fastestgrowing industries [8]. In fact, integrating IoT features into medical devices improves the quality of service, allowing a secure and efficient supervision for patients. Thus, a realtime IIOThealth monitoring infrastructure, combining various objects and defining the communication technology used for data exchanging, becomes an innovative solution for continuous patient care [9]. The potential use of various types of devices such as mobile devices, sensors, people with wireless communication via mobile internet access perform personalized healthcare services [10].

- IoT in Smart Agriculture: Due to the negative effect of industrialized agriculture on the environment and its limited productivity level, it is important to propose agriculture information based on IOT technology [11]. The smart agriculture obtained by a combination between IoT and RFID based on control platform management system and intelligent sensors enables an accurate control and real-time decision-making.

- IoT and manufacturing: IoT devices improve the productivity of manufacturing operations. It provides a tremendous growth of data volume with an accurate analyze [12]. In other hand, it is necessary to adopt IoT at production level to improve energy 
consumption and to be aware about the production management. A new business model can promise a scalable monitoring system and enlarge the consumer market [13].

- IoT for industry security: Authors in [14] declare that to make a deep study about the security of difficult industrial systems is necessary to raise the quality of monitoring process and drive the pervasiveness of security. Considering security at the design phase ensures a great time management and limits the system financial loss.

- IoT for safe environment: To save the environment from several disasters is a primordial task that requires to be more and more investigated. Various environmental fields are concerned to be extremely supervised such as the fluid distribution monitoring [15], Dam monitoring [16], ocean monitoring [17] and so on. In [17], authors highlight a System of IoT based on Smart services (SIS) for Ocean Fishing Vessel Industry to share and explore services in order to create a new business model based on smart information strategy.

In the rest of the paper, we will investigate more on the IoT-enabled Fluid Distribution Monitoring System solutions.

\section{IOT FOR FLUID DISTRIBUTION MONITORING SYSTEM (FDMS)}

Several works are implemented to monitor the Fluid system but in the context of IoT based solutions for such issue, few works are investigated. In this paper, we will provide a literature review about IoT-based solutions for Fluid Distribution Monitoring system which includes Water Distribution networks and Oil \& Gas Distribution networks as shown in figure 1. The general IOT-based Architecture for FPMS is depicted in figure 2 that presents the system architecture combined with the software modules composed by four layer (the Data layer includes data collection and data storage layers, the Network layer, the Application layer includes service layer and business layer and the Interaction layer).

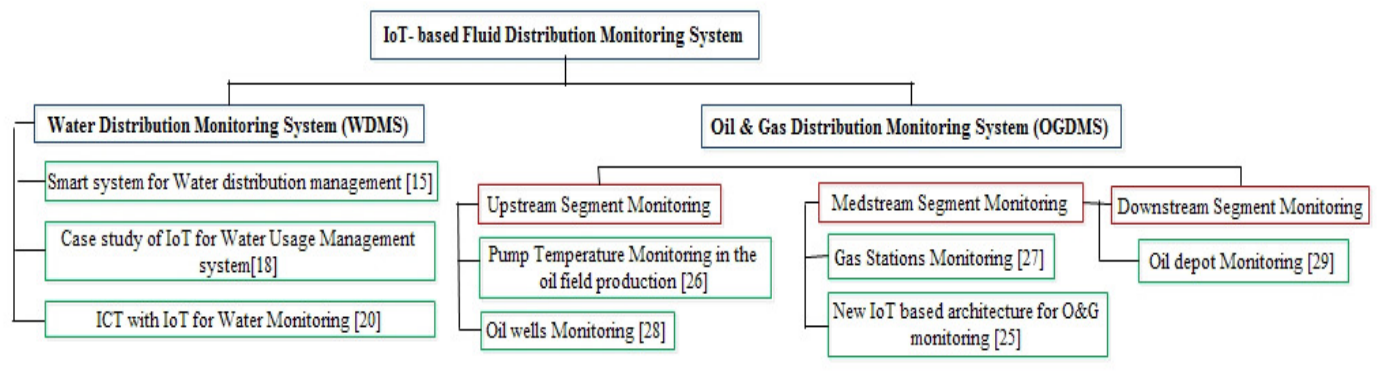

Figure 1. IOT Fluid applications in Industry

\subsection{IoT-based Water Distribution Monitoring System}

Authors in [18] define a case study of IoT for Water Usage Management system developed in Loughborough University in the UK and deployed in Sosnowiec in Poland and Skiathos in Greece. They report a comprehensive system based on IoT where they detail each phase of the implemented architecture by citing its main characteristics, proper configuration, used standards, software and hardware, etc. They used the water flow rate and temperature as data sources to monitor the water system. The application results and its assessments are carefully listed. The major lessons learned as they declared in their paper are: 
- The necessity of an integrated system to ensure end-to-end data delivery in order to limit the human intervention in network stability.

- The use of a single data access interface as a solution to make an harmony between historical data and real-time data for the reason to guarantee a continuous data access and for a better interpreting data changes.

- A distributed Data base instead of a central one ensures the continuity of the system and provides high availability and fault tolerance.

- The importance of an on-line data management system to allow a transparent authorization to data access in-time.

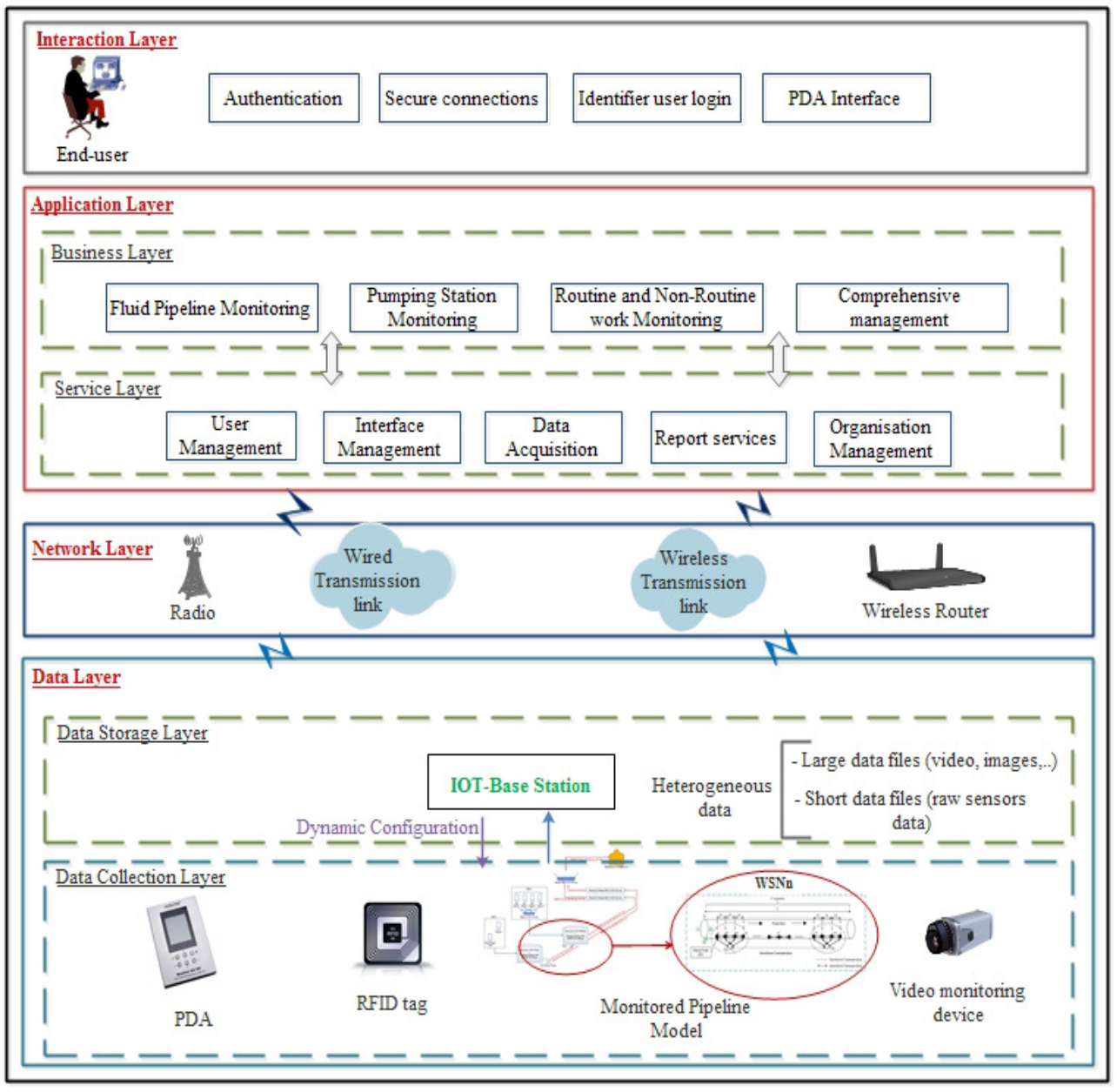

Figure 2. General IOT-based architecture for FDMS

In [19], authors suggest the automation of water supply system which is performed based on IOT. They detail the specific followed operations of the implemented round robin method. This method is applied for allocation of water in the residual areas in a centralized way. In this context, the monitoring process is based on master-slave system. The master is the central water supplier which will provide water to slave units presenting houses through Selonoid Relay nodes. To 
calibrate the water consumption level, the water is supplied taking into account priority criteria. If the level is exceeded, an alert will be sent to the administrator and there will not be an additional water supply to the home concerned by this over consumption. Robles et al. in [20] reveal the lack of a reference model for the use of Information and Communication Technologies (ICT) in the field of water management. This problem is one among several described challenges that restrict the definition of industrial standards for water management. Consequently, in order to overcome these problems and implement a reliable water distribution system, authors present the MEGA [21] model as a performant reference for smart water management and detail its main layers. Then, they introduce their proposed requirements to improve the model considering its flexibility and the interoperability as main evaluation criteria.

To adapt concepts of IOT on smart environments taking into account the ICT technologies provide a real-time monitoring, scalable system that can deploy various subsystems. In addition to IOT, OPC UA (Object Linking and Embedding for Process Control) was developed as an open standard specification that allows the communication of real-time between different industries based on web services technology.

This system is improved in [22] where authors add more layers and interfaces in the deployed architecture. They consider the basic relationship between the physical and process models to define an hierarchical execution of physical elements and their better organization. Although the important role of such architecture for water management system, it still insufficient in case of other complex real problems. To solve this problem taking into account its large physical resources presents the future work to be held.

Authors in [23] present a proposed smart system to enhance the water distribution management for India using IoT. They introduce the use of the mobile phone of every Indian citizen and the valve used to calibrate water as embedded based water flow sensors to transmit data to the remote control centre. Accordingly, it will be easier to detect leakages and damage along the water pipeline.

\subsection{IoT-based O\&G Distribution Monitoring System (OGDMS)}

The Oil and Gas companies aim to enhance reliability and optimize their operations in order to improve their business and reduce disruptions. Consequently, recently, these industries start working with data-management and integrate IoT in their applications. Oil and Gas industry value chain is divided into three main sectors: Upstream, Midstream and Downstream [24]. IoT technology can be applied either to monitor the segment where Exploration and Production of Oil and Gas i.e drilling exploratory wells (Upstream sector), the Pipelines companies that manage the pipelines that control the flow of oil (Midstream sector) or the segments where oil is cooked to make gasoline, diesel, jet fuel, etc. (Downstream sector). In [25], a novel IoT based architecture is presented to optimize the data collection from connected objects for the oil and gas industries. For each architecture layer and with each O\&G sector, authors define the specificities of the implemented monitoring modules, their characteristics, equipments, used functions and technologies that support the robustness of each layer.

A design of new oil pump temperature monitoring system based on IoT is depicted in [26]. A smart real time collection of pump temperature data, during the oil production, promises useful information that allows recognizing the pump behaviour. In addition, if the temperature value surpasses a threshold value, a fault diagnosis system is implemented to alert the operator to make the appropriate action. 
Authors in [27] aim to address a new IoT based system to monitor real time information of gas stations through a social network. Cloud storage is used to store collected data in order to have easy access to historical and new data remotely. This intelligent system comes to cope with the traditional gas station management based on manual monitoring and limited data resources and offer new original monitoring process with efficient data operation combined with accurate management.

Author in [28] addresses that Industrial Internet of Things use General Electric GEs Predix Software Platform to monitor and predict the performance and failure of wells. He notes that prevention of unplanned outages via the Industrial Internet of Things can save an operator up to 3 million per week which would otherwise have to be spent if a well goes out of production.

An IoT based management system is introduced in [29] to provide a remote supervision for oil depot. The proposed system is used to protect automatically the environment and to create a secure and workable system. Architecture of three layers is implemented composed by: the sensing layer consists of RFID tags and Personal Digital Assistants (PDA) employed to collect oil depot services. A communication layer used to send information gathered from the workplace to the control server where the safety management information system will be implemented.

\section{SYNTHESIS}

\subsection{Comparative studies of existing applications}

Under the concept of Industry 4.0, each IoT-based application presents its specific characteristics, material and monitoring system model. Table 1 provides a comparison between the applications detailed below and resumes their used techniques, equipments and technologies. In addition, according to the advantages noted in Table 1, it is revealed that the IoT integration enables efficient industry applications, optimizes its monitoring operations, creates new values and helps companies to transform their business. The collaboration between various smart equipments, technologies and the structured proposed systems ensure its interoperability and capability and guarantee an accurate and clear objective. Wireless networks are used by most applications in order to allow a continuous communication and an efficient data exchange between devices.

\subsection{Evaluation of existing applications}

The evaluation process is a crucial step permitting a relevant assessment of an achievement against various criteria and it follows different methods [30]. In this context, in order to identify the robustness and performance level of the previous detailed works, we try to evaluate and extract their main characteristics.

Researchers proposed several evaluations methods and categorized them into diverse classes such as:

- Data driven evaluation: this method determines the similarity level between obtained results and other source of data.

- Human-based evaluation: The objective is to determine the conformity between the system and the user specifications. For this, the usability technique [31] is used to develop systems interfaces especially for complex systems and to depict how much the resulted system is similar to the target one. It presents four evaluation criteria such as the flexibility, operability, learnability and understandability. 
- Criteria-based evaluation: This type of evaluation considers a set of criteria to evaluate the system functionality such as: Intelligence, security.

We select the second and third approaches to evaluate the proposed systems as exposed in Table 2.

Table 1. Comparison of existing IoT- based Fluid Monitoring System Applications

\begin{tabular}{|c|c|c|c|c|}
\hline & Material & Architecture/Medium & Advantages & Drawbacks \\
\hline \multicolumn{5}{|c|}{ IoT-based Water Distribution Monitoring System } \\
\hline [15] & $\begin{array}{l}\text {-Liquid level sensor } \\
\text {-Flow meters } \\
\text {-Automatic weather } \\
\text { station } \\
\text {-Light source, PLC } \\
\text { modules }\end{array}$ & $\begin{array}{l}\text {-Service-Oriented } \\
\text { Architecture } \\
\text {-Layered Architecture } \\
\text {-Wireless transmission }\end{array}$ & $\begin{array}{l}\text {-Application framework } \\
\text { based on SOA and IoT } \\
\text {-Centralized } \\
\text { management of massive }\end{array}$ & - \\
\hline [18] & $\begin{array}{l}\text {-Wireless Data } \\
\text { collector } \\
\text {-Wireless Gatewey } \\
\text {-Wifi Gateway } \\
\text {-Flow rate / } \\
\text { temperature } \\
\text {-Flow sensors }\end{array}$ & $\begin{array}{l}\text {-Star communication } \\
\text {-3 layer architecture } \\
\text {-Wireless }\end{array}$ & $\begin{array}{l}\text { - Remote IoT -based } \\
\text { application through real } \\
\text { implementation } \\
\text {-No data collision } \\
\text {-Energy saving } \\
\text {-Regular system } \\
\text {-On-line configuration }\end{array}$ & $\begin{array}{l}\text {-Human } \\
\text { intervention in } \\
\text { the monitoring } \\
\text { system. } \\
\text {-Central Data } \\
\text { Base }\end{array}$ \\
\hline [20] & - & $\begin{array}{l}\text {-Hierarchical topology } \\
\text {-High level architecture } \\
\text {-Wireless }\end{array}$ & $\begin{array}{l}\text {-Manageable and } \\
\text { interoperable } \\
\text { equipments } \\
\text {-Open standard interface }\end{array}$ & $\begin{array}{l}\text {-No integrated } \\
\text { solutions } \\
\text {-Coupled } \\
\text { architecture }\end{array}$ \\
\hline \multicolumn{5}{|c|}{ IoT-based O\&G Distribution Monitoring System } \\
\hline [25] & $\begin{array}{l}\text {-Acoustic, } \\
\text { Temperature sensors. } \\
\text {-Flow and pressure } \\
\text { sensors. } \\
\text {-RFID tags. }\end{array}$ & $\begin{array}{l}\text { Short/long range } \\
\text { communication } \\
\text { technology }\end{array}$ & $\begin{array}{l}\text {-Continuous monitoring. } \\
\text {-Minimum human } \\
\text { intervention. } \\
\text {-Predictive maintenance }\end{array}$ & - \\
\hline [26] & $\begin{array}{l}\text {-ARP- S3C2410 chip } \\
\text { DS18b20 } \\
\text {-Temperature Sensor }\end{array}$ & Three layer architecture & $\begin{array}{l}\text {-Flexible interface. } \\
\text {-Has a good scalability. }\end{array}$ & - \\
\hline$[27]$ & $\begin{array}{l}\text {-Liquid level } \\
\text { detection sensor } \\
\text {-Temperature and } \\
\text { Flow sensors } \\
\text {-Minnow IoT } \\
\text { Gateway }\end{array}$ & $\begin{array}{l}\text {-Hierarchical network } \\
\text { Architecture } \\
\text {-Internet communication } \\
\text { protocol WebSocket } \\
\text {-Wireless } \\
\text { Communication. }\end{array}$ & $\begin{array}{l}\text { - Online services for } \\
\text { people } \\
\text {-Cloud Storage } \\
\text {-Software with the } \\
\text { advantage of portability. } \\
\text {-Provides a huge user } \\
\text { market. }\end{array}$ & $\begin{array}{l}\text { - Centred } \\
\text { information } \\
\text { processing }\end{array}$ \\
\hline [29] & $\begin{array}{l}\text {-RFID tags } \\
\text { - Explosion-proof } \\
\text { PDA }\end{array}$ & $\begin{array}{l}\text {-3 layer Architecture } \\
\text { - Communication } 3 \mathrm{G} \\
\text { - Software adopted: } \\
\text { Oracle for storing } \\
\text { business data, others are } \\
\text { encapsulated } \\
\text { as web service. }\end{array}$ & $\begin{array}{l}\text { - Proven record in real } \\
\text { depot sites }\end{array}$ & - \\
\hline
\end{tabular}


Table 2. Evaluation of the IIoT-FDMS applications

\begin{tabular}{|l|l|l|l|l|l|}
\hline \multicolumn{4}{|l|}{ Human-Based Evaluation } & Criteria-Based Evaluation \\
\hline & Flexibility & Operability & Learnability & Intelligence & Security \\
\hline$[15]$ & + & + & + & + & - \\
\hline$[18]$ & - & + & + & - & - \\
\hline$[20]$ & + & - & + & + & + \\
\hline$[25]$ & + & + & + & + & + \\
\hline$[26]$ & + & + & + & + & - \\
\hline$[27]$ & + & + & - & + & + \\
\hline$[29]$ & + & + & + & + & - \\
\hline
\end{tabular}

\section{IIOT FDSM CHALLENGES}

Although, the great role of IOT in different application domains and its performance to provide accurate monitoring systems, this technology presents various challenges that would be overcome. Open challenges are discussed based on the IoT elements presented earlier. Many researchers were interested to enumerate these challenges in their works such as in [22], authors list IoT problems as follow:

- Complex interaction between water resources and environment system.

- Complicated solution based on diverse standards and methods.

- Lack of common standard for equipment internetworking.

- Insufficient knowledge for supporting ICT to understand water distribution process.

- Complicated supplier systems due to the lack of standardization.

Other authors [32] define the Industrial IoT FDMS challenges as privacy, sensing, data analytics, the standard WSN challenges including architecture, energy efficiency, security, protocols, and Quality of Service. Researchers tried to address these technical challenges in order to extend the network lifetime and to avoid any drawbacks. Authors in [33] focused on:

- Energy in IIOT FDMS: Therefore, the energetic limit is the most constraint in the IIoT FDMS design. It effects the network lifetime especially when supporting a variety of IoT entities. For this reason, to conserve the energy is the main goal. Researchers surveyed the different energy dissipation modes and sources of the overconsumption energy by the sensor node. Different mechanisms for energy conservation were overviewed such as the hierarchical topology based on clustering, the data aggregation and fusion and that directly influenced the network life time.

- Security in IIOT FDMS: A security model based on the concept of trust should be used in the system distributed surveillance. In this case, technical mechanisms must be at service of the security strategy. Therefore, too restrictive strategy enables little interaction and thus makes the system inoperative. It is the same with a very permissive strategy that eliminates the trust between users. In addition to the trust conception, the security is based on privacy of data. Then, it is a crucial task to protect the data referring to individual users from exposure in the IoT environment. Any physical or logical entity or object can be given a unique identifier and be able to communicate autonomously over the Internet or similar network. 


\section{CONCLUSION}

In this paper, an investigation on Industrial IoT is carried on with various application domains. The wide use of such technology in various fields reveals its great importance and its efficient provided solutions to improve application results. The Fluid Distribution Monitoring System is also concerned by IoT services which improve the monitoring process and allow a real time management and data processing. Recent researches are investigated and described in order to prove the important role of this new smart technology and to evaluate their proposed architectures and systems. The main recapitulated insights are that IoT is an adequate solution to benefit smartly from IT services and operate under harmonious data access and data management. Therefore, companies that are responsible for Fluid transportation or requiring it in their production cycle are able to face considerable upside in improving pipeline safety and to handle a design of workable system. This development can guarantee the future success of industries and create new clear business objectives. IoT becomes a source of Big quantity of data obtained from heterogeneous and dynamic connected objects. For that, as future work, we will focus on managing and storing this data in a scalable way.

\section{REFERENCES}

[1] F. Wortmann, K. Fluchter “ et al., "Internet of things," Business \& Information Systems Engineering, vol. 57, no. 3, pp. 221-224, 2015.

[2] O. Monnier, "A smarter grid with the internet of things," Texas Instruments, 2013.

[3] K. Schwab, The fourth industrial revolution. Penguin UK, 2017.

[4] S. Wang, J. Wan, D. Li, and C. Zhang, "Implementing smart factory of industrie 4.0: an outlook," International Journal of Distributed Sensor Networks, 2016.

[5] C. Perera, C. H. Liu, S. Jayawardena, and M. Chen, "A survey on internet of things from industrial market perspective,” IEEE Access, vol. 2, pp. 1660-1679, 2014.

[6] L. Da Xu, W. He, and S. Li, "Internet of things in industries: A survey," IEEE Transactions on industrial informatics, vol. 10, no. 4, pp. 2233-2243, 2014.

[7] M. Zarei, A. Mohammadian, and R. Ghasemi, "Internet of things in industries: a survey for sustainable development," International Journal of Innovation and Sustainable Development, vol. 10, no. 4, pp. 419-442, 2016.

[8] Y. C. Wang, K. McPherson, T. Marsh, S. L. Gortmaker, and M. Brown, "Health and economic burden of the projected obesity trends in the USA and the UK," The Lancet, vol. 378, no. 9793, pp. 815-825, 2011.

[9] M. S. Hossain and G. Muhammad, "Cloud-assisted industrial internet of things (IIOT)-enabled framework for health monitoring," Computer Networks, vol. 101, pp. 192-202, 2016.

[10] I. Plaza, L. Martin, S. Martin, and C. Medrano, "Mobile applications in an aging society: Status and trends," Journal of Systems and Software, vol. 84, no. 11, pp. 1977-1988, 2011.

[11] F. TongKe, "Smart agriculture based on cloud computing and IOT," Journal of Convergence Information Technology, vol. 8, no. 2, 2013. 
[12] F. Shrouf, J. Ordieres, and G. Miragliotta, "Smart factories in industry 4.0: A review of the concept and of energy management approached in production based on the internet of things paradigm," in Industrial Engineering and Engineering Management (IEEM), 2014 IEEE International Conference on. IEEE, 2014, pp. 697-701.

[13] A. Khan and K. Turowski, "A survey of current challenges in manufacturing industry and preparation for industry 4.0," in Proceedings of the First International Scientific Conference Intelligent Information Technologies for Industry (IITI16). Springer, 2016, pp. 15-26.

[14] C. Alcaraz, R. Roman, P. Najera, and J. Lopez, "Security of industrial sensor network-based remote substations in the context of the internet of things," Ad Hoc Networks, vol. 11, no. 3, pp. 1091-1104, 2013.

[15] X. Liu, H. Liu, Z. Wan, T. Chen, and K. Tian, "Application and study of internet of things used in rural water conservancy project," Journal of Computational Methods in Sciences and Engineering, vol. 15 , no. 3 , pp. $477-488,2015$.

[16] N. Mohod, "Usability of internet of things [iot] for dam safety and water management."

[17] C. M. Chen, L. J. Yu, P. L. Ling, J. S. Yang, and S. Q. Cao, "The architecture of iot smart service system of ocean fishing vessel and its application based on petri net," in Applied Mechanics and Materials, vol. 385. Trans Tech Publ, 2013, pp. 1771-1775.

[18] S.-H. Yang, X. Chen, X. Chen, L. Yang, B. Chao, and J. Cao, "A case study of internet of things: A wireless household water consumption monitoring system," in Internet of Things (WF-IoT), 2015 IEEE 2nd World Forum on. IEEE, 2015, pp. 681-686.

[19] R. Ukkali and D. Geetha, "Automated water distribution system based on iot."

[20] T. Robles, R. Alcarria, D. Mart’in, A. Morales, M. Navarro, R. Calero, S. Iglesias, and M. Lopez, "An internet of things-based model for smart water management," in Advanced Information Networking and Applications Workshops (WAINA), 2014 28th International Conference on. IEEE, 2014, pp. 821-826.

[21] "Mega project homepage: http://www.gestiondelagua.es/en/."

[22] T. Robles, R. Alcarria, D. Mart'in, M. Navarro, R. Calero, S. Iglesias, and M. Lopez, "An iot based reference architecture for smart water management processes," J. Wirel. Mob. Netw. Ubiquit. Comput. Dependable Appl, vol. 6, no. 1, pp. 4-23, 2015.

[23] S. Ezhilvanji and S. Malarkodi, "An efficient water distribution system for india using iot."

[24] A. Slaughter, G. Bean, and A. Mittal, "Connected barrels: Transforming oil and gas strategies with the internet of things," 2015.

[25] W. Z. Khan, M. Y. Aalsalem, M. K. Khan, M. S. Hossain, and M. Atiquzzaman, "A reliable internet of things based architecture for oil and gas industry," in Advanced Communication Technology (ICACT), 2017 19th International Conference on. IEEE, 2017, pp. 705-710.

[26] D.-x. Wang, Y.-j. Xu, Z. Li, and Y.-p. Zhu, "Design of the oil pump temperature monitoring system based on internet of things," in Advanced Research and Technology in Industry Applications (WARTIA), 2014 IEEE Workshop on. IEEE, 2014, pp. 831-833.

[27] H. Cui, T. Xu, X. Jiang, and L. Fang, "Gas stations oriented internet service system based on intel minnowboard," in Computational Intelligence and Design (ISCID), 2016 9th International Symposium on, vol. 1. IEEE, 2016, pp. 290-293. 
[28] P. Kendon, "5 innovative technologies changing maintenance management in the oil and gas sector," in Available via: http://www.solufy.com/blog/5-innovativetechnologies-disrupt-maintenancemanagement. [Accessed: 29.01.2017], 2016.

[29] Z. Du, Y. Mao, and M. Lu, "Design and implementation of safety management system for oil depot based on internet of things," in Green Computing and Communications (GreenCom), 2012 IEEE International Conference on. IEEE, 2012, pp. 249-252.

[30] M. Kim, “A quality model for evaluating iot applications," International Journal of Computer and Electrical Engineering, vol. 8, no. 1, p. 66, 2016.

[31] M. O. Thomas, B. A. Onyimbo, and R. Logeswaran, "Usability evaluation criteria for internet of things," 2016.

[32] J. Gubbi, R. Buyya, S. Marusic, and M. Palaniswami, "Internet of things (iot): A vision, architectural elements, and future directions," Future generation computer systems, vol. 29, no. 7, pp. 1645-1660, 2013.

[33] D. Miorandi, S. Sicari, F. De Pellegrini, and I. Chlamtac, "Internet of things: Vision, applications and research challenges,” Ad Hoc Networks, vol. 10, no. 7, pp. 1497-1516, 2012.

\section{AUTHORS}

\section{Maroua Abdelhafidh}

Obtained her Bachelor degree in Management computer and Electronic Commerce and her masters in Computer Science and Multimedia from SFAX University, TUNISIA. Currently, she is a PhD Student at the National Engineering School (ENIS). She is a researcher at the Research Laboratory of Technology and Smart Systems (LT2S), Digital Research Center of Sfax (CRNS). Her current doctoral research area is in wireless communication, wireless sensor network, hydraulic pipeline monitoring and signal processing.

\section{Mohamed Fourati}

He obtained the engineering degree in electrical and electronic engineering from Higher Normal School Technical Studies, Tunisia in 1992, and master thesis degree from Sfax National Engineering School, Tunisia in 2008. Currently, he is an assistant professor in Multimedia and Informatics Higher Institute, Sfax. He is researcher in Laboratory of Technology and Smart Systems (LT2S), Digital Research Center of Sfax (CRNS). His scope of research is channel coding.

\section{Lamia Chaari Fourati}

She received the engineering and $\mathrm{PhD}$ degrees in electrical and electronic engineering from SFAX National Engineering School (ENIS) in TUNISIA. She received in 2011 HDR telecommunications from ENIS. Currently, she is an associate professor at multimedia and informatics higher institute, SFAX University, TUNISIA. She is also a researcher at Research Laboratory of Technology and Smart Systems (LT2S), Digital Research Center of Sfax (CRNS). Her scope of research are new generation networks, communications, wireless networking, multiple access and MAC design, QoS provisionning, IoT, M2M, SDN, ICN.
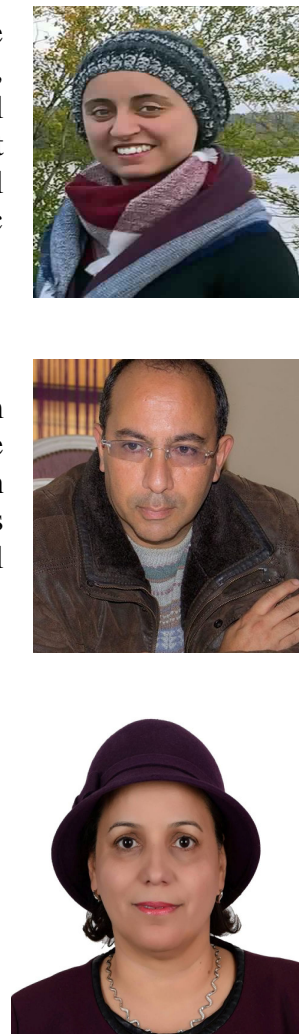